\title{
Perfil de profissionais de enfermagem e ocorrências éticas*
}

\author{
Nursing professionals profile and ethical occurrences \\ El perfil de profesionales de enfermería y ocurrencias éticas
}

\author{
Genival Fernandes de Freitas ${ }^{1}$, Taka Oguisso ${ }^{2}$
}

\section{RESUMO}

Objetivo: Descrever o perfil dos profissionais de enfermagem envolvidos em ocorrências éticas de um determinado hospital. Métodos: Estudo de natureza retrospectiva e exploratória com abordagem quantitativa.Os dados foram obtidos de ficha previamente preparada, coletando informações registradas pelos membros da Comissão de Ética de Enfermagem (CEE) desse hospital, no período de 1995 a 2004. Resultados: A análise revelou as distribuição de ocorrências de acordo com faixa etária, sexo, função, jornada de trabalho, tempo de serviço e sobre quem comunicou essas ocorrências à CEE. Conclusão: Dados têm favorecido parcerias para um processo educativo integrado da CEE, da Comissão de Educação Continuada e gerências de enfermagem, apontando áreas que carecem de investimentos para prevenção dessas ocorrências.

Descritores: Ética de enfermagem; Ética; Equipe de enfermagem/ética

\begin{abstract}
Objective: to describe the profile of nursing professionals involved in ethical occurrences in a specific hospital. Methods: this is a retrospective, exploratory study using a quantitative approach. Results: data obtained with a previously created form, used to collect information recorded by members of the Nursing Ethics Committee (NEC) of the referred hospital, between 1995 and 2004. Analysis showed distribution of occurrences according to age group, gender, job position, working hours, time in the job, and the person who reported the occurrence to NEC. Conclusion: Data have favored partnerships for an educational process involving the NEC, Continuing Education Program, and the nursing managers, pointing out areas that need more investment to prevent these ethical occurrences.
\end{abstract}

Descriptors: Nursing ethics; Ethics; Nursing team/ethics

\section{RESUMEN}

Objetivo: Describir el perfil de los profesionales de enfermería involucrados en ocurrencias éticas de un determinado hospital. Métodos: Se trata de un estudio de naturaleza retrospectiva y exploratoria con abordaje cualitativo. Los datos fueron obtenidos de una ficha previamente preparada, la cual permitió la recolección de informaciones registradas por los miembros de la Comisión de Ética de Enfermería (CEE) de ese hospital, en el período de 1995 al 2004. Resultados: El análisis reveló la distribución de ocurrencias de acuerdo al grupo etáreo, sexo, función, jornada de trabajo, tiempo de servicio y sobre quién comunicó las ocurrencias a la CEE. Conclusión: Los datos han favorecido sociedades para un proceso educativo integrado de la CEE, de la Comisión de Educación Continuada y gerencia de enfermería, señalando áreas que carecen de inversiones para la prevención de esas ocurrencias.

Descriptores: Ética de enfermería; Ética; Equipo de enfermería/ética

\footnotetext{
* Trabalho realizado no Departamento Departamento de Orientação Profissional da Escola de Enfermagem da Universidade de São Paulo - USP - São Paulo (SP), Brasil.

${ }_{1}$ Doutor, Professor do Departamento de Orientação Profissional da Escola de Enfermagem da Universidade de São Paulo - USP - São Paulo (SP), Brasil; Advogado - São Paulo (SP), Brasil.

${ }^{2}$ Professora Titular do Departamento de Orientação Profissional da Escola de Enfermagem da Universidade de São Paulo - USP - São Paulo (SP), Brasil.
} 


\section{INTRODUÇÃO}

A Enfermagem vem se desenvolvendo com base em conhecimentos empíricos e teóricos fundamentados em múltiplas atividades profissionais voltadas para a assistência, o ensino, o gerenciamento e a pesquisa. Nesse desenvolvimento da profissão, é levado em consideração o processo de trabalho da equipe de enfermagem, a fim de propiciar uma assistência segura e isenta de riscos ou de danos à clientela. Faz-se mister que os profissionais de enfermagem conheçam as normas legais que regulamentam os direitos e as obrigações relativos ao exercício da profissão. Contudo, esse conhecimento não deve significar a substituição das dimensões ética e moral que permeiam as ações desses profissionais.

Nesse sentido, o Código Civil Brasileiro de 2002, art. 186 estabelece "aquele que, por ação ou omissão, negligência ou imprudência, violar direito e causar dano a outrem, ainda que exclusivamente moral, comete ato ilícito"(1). O ato ilícito consiste na obrigação de indenizar e só haverá indenização quando houver dano a ressarcir, podendo esse dano ser de ordem física (por exemplo, lesão corporal culposa) e/ou de ordem moral, quando pode haver além da ofensa à integridade física, um sofrimento espiritual ou um constrangimento à pessoa ${ }^{(2)}$.

Negligência, imperícia ou imprudência podem resultar em ocorrências éticas por parte dos profissionais de enfermagem, podendo expor o paciente/cliente a situações de riscos ou de danos à integridade física ou moral, mesmo que não haja a intenção deliberada desses profissionais de ocasionar esses danos ao cliente.

As ocorrências éticas são aquelas situações que se referem às atitudes inadequadas frente ao colega de trabalho ou subordinados, englobando falhas ou erros que podem causar prejuízos ou danos ao paciente/cliente, à equipe de trabalho e/ou à instituição $\mathrm{O}^{(3)}$.

Embora as Comissões de Ética de Enfermagem (CEE) tenham mais de uma década de existência, o papel educativo, face às ocorrências éticas, tem se mostrado bastante incipiente ${ }^{(3)}$. Por outro lado, há que se considerar o fato de que as ocorrências éticas não se restringem às falhas técnicas devido às dificuldades ou erros na execução de procedimentos.

As ocorrências éticas podem, também, ser resultantes de dificuldades nas relações interpessoais ou interprofissionais, por exemplo, quando essas relações se revelam desrespeitosas. Estudo realizado com 18 enfermeiros participantes de CEE, acerca do papel desse órgão nas instituições de saúde que trabalham, revelou que as percepções desses enfermeiros abrangem as instâncias das relações humanas, passando pelo respeito, pelo bom relacionamento, sigilo, obediência às normas e leis. Revelou, também, a preocupação desses enfermeiros com a busca contínua do processo de melhoria da qualidade da assistência prestada ao paciente/cliente, assegurando o respaldo legal ao funcionário no cumprimento de seus deveres e na defesa dos seus direitos $^{(3)}$.

É dever ético garantir um atendimento isento de eventos prejudiciais ao cliente, de acordo com o art. 16 do Código de Ética dos Profissionais de Enfermagem ${ }^{(4)}$. Por conseguinte, é um direito dos pacientes/clientes dos serviços de enfermagem que lhes sejam assegurados que os riscos sejam evitados pelos profissionais que os assistem. Poderá haver concomitância de responsabilidades ética, civil, ou mesmo penal por parte do profissional envolvido em ocorrência ética, quando os riscos forem previsíveis ou evitáveis ${ }^{(5)}$. Também é um direito do paciente/cliente de enfermagem, que sejam fornecidas as informações sobre os riscos, os benefícios e os custos, bem como as medidas tomadas para minimização das ocorrências éticas danosas à clientela ${ }^{(0)}$. Essas ocorrências podem também ser denominadas iatrogenias.

As ocorrências iatrogênicas são eventos, fatos ou ocorrências que se desviam do curso normal e esperado de um tratamento ou de um cuidado, podendo acarretar resultados prejudiciais ao cliente, à instituição, ou ao próprio profissional de saúde ${ }^{(7)}$. Ademais, as iatrogenias podem resultar das ocorrências éticas, considerando-se as possibilidades de falhas ou erros cometidos pelos profissionais de enfermagem, os quais podem dar causa a algum tipo de prejuízo ou dano, seja de natureza física, ou mesmo moral, em relação ao paciente/cliente, em relação ao colega de trabalho ou ao estabelecimento de saúde.

Outro aspecto relevante nas ocorrências éticas ou iatrogênicas refere-se à questão das responsabilidades, seja dos profissionais ou das empresas prestadoras de serviços de saúde. Assim, ocorrendo um erro de dosagem de medicação, envolvendo profissionais de enfermagem, o enfermeiro decidirá o que fazer no momento da ocorrência e quais os encaminhamentos a serem dados. Assim, ao hospital caberá a obrigação de indenizar ou descaracterizar a denúncia do paciente/cliente/família, comprovando que o erro alegado não ocorreu. Também poderá o hospital alegar que houve culpa exclusiva do profissional, pois embora dispondo de recursos físicos/ materiais e competência técnica/legal, o mesmo provocou um erro por culpa dele e não da empresa. Desse modo, poderá ser reconhecido o direito do paciente/cliente à "[...]facilitação da defesa de seus direitos, inclusive com a inversão do ônus da prova, a seu favor [...] quando for verossímil a alegação ou quando for ele hipossuficiente [...]", art. 6. ${ }^{\circ}$, inciso VIII do Código de Defesa e Proteção do Consumidor ${ }^{(8)}$.

\section{OBJETIVO}

Descrever o perfil dos profissionais de enfermagem 
envolvidos em ocorrências éticas, em relação ao sexo, faixa etária, jornada de trabalho, tempo de serviço na instituição e sobre as pessoas que comunicaram tais ocorrências à CEE, no período de 1995 a 2004.

Tendo em vista essas considerações, indaga-se: qual seria o perfil dos profissionais de enfermagem envolvidos em ocorrências éticas?

A hipótese do presente estudo consiste em que os auxiliares de enfermagem são os profissionais mais envolvidos nas ocorrências éticas, sendo eles responsáveis por maior número dessas ocorrências no cuidado direto ao paciente.

O conhecimento do perfil dos profissionais de enfermagem envolvidos nas ocorrências éticas no contexto hospitalar poderá orientar políticas institucionais no sentido de investir e valorizar a atuação conjunta de enfermeiros e de outras categorias de enfermagem, para um processo educativo e preventivo desses eventos.

\section{MÉTODOS}

Trata-se de um estudo de natureza retrospectiva e descritiva, realizado em um hospital particular do Município de São Paulo, de aproximadamente 200 leitos, com caráter jurídico de instituição sem fins lucrativos com finalidade de atendimento médico, clínico e cirúrgico. O seu corpo de enfermagem tem $14 \%$ de enfermeiros e $86 \%$ de auxiliares de enfermagem e técnicos de enfermagem.

Após a definição do problema de pesquisa, e feitas a delimitação do objetivo e a seleção de hipóteses a serem trabalhadas neste estudo, foi realizado um pré-teste das variáveis em campo, com três enfermeiros membros da CEE da instituição alvo do estudo, a fim de verificar se o instrumento proposto apresentava fidedignidade, validade e operatividade. Depois do pré-teste, o instrumento foi modificado, ampliado e alguns itens eliminados, bem como, definidas as variáveis envolvidas na pesquisa.

A coleta dos dados foi realizada após aprovação do Comitê de Ética em Pesquisa, da instituição alvo do estudo, seguindo um formulário previamente elaborado pelos pesquisadores, contendo os dados de identificação dos profissionais de enfermagem envolvidos em ocorrências éticas, considerando as seguintes variáveis: sexo, faixa etária, função, percentual de profissionais de enfermagem atuantes na instituição por categoria (no período estudado), jornada de trabalho e tempo de serviço na instituição, bem como identificação das pessoas que comunicaram tais ocorrências à CEE. Os itens levantados deram origem às variáveis quantitativas, as quais assumiram valores numéricos e possibilitaram um estudo correlacional e associativo das variáveis pertinentes ao objeto e ao objetivo deste estudo.

A população alvo de investigação deste estudo foi constituída pelo conjunto de ocorrências éticas que foram observadas no local da pesquisa no período de 1995 a 2004. A amostra trabalhada neste estudo foi constituída por 186 ocorrências éticas que foram encaminhadas à CEE daquela instituição no período estabelecido para o estudo, mencionado anteriormente.

Os critérios para inclusão na amostra foram:

* existência de denúncia formalmente encaminhada à CEE sobre fato tido como ocorrência ética no período de 1995 a 2004;

* ser profissional de enfermagem, registrado na instituição alvo do estudo.

Os dados foram organizados em tabelas e medidas resumo para serem trabalhados segundo os métodos da análise descritiva. Foram utilizados os procedimentos estatísticos de análise inferencial, propostos por Stevenson $^{(9)}$ e Siegel $^{(10)}$ :

\section{RESULTADOS}

Tabela 1 - Distribuição dos profissionais de enfermagem envolvidos nas ocorrências éticas registradas, segundo o sexo. São Paulo, 2005.

\begin{tabular}{lcc}
\hline Sexo & $\mathbf{N .}^{\mathbf{o}}$ & $\mathbf{\%}$ \\
\hline Masculino & 67 & 36,0 \\
Feminino & 119 & 64,0 \\
\hline Total & $\mathbf{1 8 6}$ & $\mathbf{1 0 0 , 0}$ \\
\hline
\end{tabular}

O exame dos dados contidos na Tabela 1 evidencia uma predominância de ocorrências registradas para profissionais do sexo feminino com $119(64,0 \%)$ das citações que foram encaminhadas para a CEE do hospital alvo do estudo. Em seguida, vêm os profissionais do sexo masculino, com $67(36,0 \%)$ das ocorrências. Essa constatação é compreensível, considerando que o maior contingente dos profissionais de enfermagem na instituição é composto por mulheres.

Tabela 2 - Distribuição das pessoas responsáveis pela comunicação da ocorrência ética à Comissão de Ética de Enfermagem no período de 1995 a 2004. São Paulo, 2005.

\begin{tabular}{lrc}
\hline Pessoa que comunicou a ocorrência & $\mathbf{N .}^{\mathbf{0}}$ & $\mathbf{0}$ \\
\hline Enfermeiro & 178 & 95,7 \\
Paciente & 1 & 0,5 \\
Família do Paciente & 4 & 2,2 \\
Médico & 2 & 1,1 \\
Auto delação & 1 & 0,5 \\
\hline Total & $\mathbf{1 8 6}$ & $\mathbf{1 0 0 , 0}$ \\
\hline
\end{tabular}

O exame dos dados contidos na Tabela 2 mostra predominância de ocorrências encaminhadas por enfermeiros, $(95,7 \%)$ do total de 186 denúncias apresentadas à CEE, no levantamento retrospectivo dos dados. Em seguida, vêm as ocorrências comunicadas pela 
família do paciente com $4(2,2 \%)$ das citações e 2 casos $(1,1 \%)$ que foram encaminhados à CEE por médicos. Houve uma ocorrência $(0,5 \%)$ em que o próprio profissional que a cometeu enviou a comunicação para a CEE e uma ocorrência $(0,5 \%)$ enviada pelo paciente/ cliente.

Diante dessa constatação, indagam-se as razões por que só os enfermeiros, dentre os trabalhadores de enfermagem, comunicaram ocorrências éticas e outras categorias não o fizeram? O técnico e o auxiliar de enfermagem têm ciência de que podem recorrer à $\mathrm{CEE}$ para delatar infrações éticas ou irregularidades cometidas por qualquer profissional da área? Qual a autonomia que dispõem para fazer uma denúncia à CEE na instituição alvo do estudo? Esses questionamentos, embora relevantes, fogem ao objetivo desse estudo, a priori. É possível que esteja ocorrendo a centralização no enfermeiro, chefe da tomada de decisão em relação ao encaminhamento ou não das ocorrências éticas à CEE, e nada cabendo às outras categorias de enfermagem.

Tabela 3 - Distribuição dos profissionais de enfermagem envolvidos nas ocorrências éticas no período de 1995 a 2004, segundo faixa etária. São Paulo, 2005.

\begin{tabular}{lrr}
\hline Faixa etária & $\mathbf{N .}^{\mathbf{0}}$ & \multicolumn{1}{c}{$\mathbf{0}$} \\
\hline $20-29$ & 37 & 19,9 \\
$30-39$ & 86 & 46,2 \\
$40-49$ & 45 & 24,2 \\
$50-59$ & 16 & 8,6 \\
$60-69$ & 2 & 1,1 \\
\hline Total & $\mathbf{1 8 6}$ & $\mathbf{1 0 0 , 0}$ \\
\hline Média & 36,86 & \\
IC95\% & 1,23 & \\
Mediana & 35,00 & \\
Moda & 30 & \\
Desvio Padrão & 8,65 & \\
Mínimo & 20 & \\
Máximo & 61 & \\
Q1 & 30,00 & \\
Q2 & 35,00 & \\
Q3 & 42,00 & \\
\hline
\end{tabular}

O exame dos dados contidos na Tabela 3 sugere predomínio de profissionais envolvidos com idade entre 30 e 39 anos com 46,2,1\% das ocorrências que foram encaminhadas à CEE no período estudado. Em seguida vêm os profissionais na faixa etária de 40 a 49 anos com $24,2 \%$; de 20 a 29 anos com $19,9 \%$; 50 a 59 anos com $8,6 \%$ e de 60 a 69 anos com 2 ocorrências $(1,1 \%)$ do total de casos analisados. Essa faixa etária é constituída, em geral, por pessoas experientes na profissão e, talvez por isso mesmo, tenham executado de forma automática, sem a atenção e o devido cuidado.

Quanto às medidas resumo, o valor médio da idade foi de 36,8 (DP=8,6), com mediana de 35,0, moda de 30 e variação de 20 a 61 anos. Também é possível observar que cerca de $20 \%$ das ocorrências foram cometidas por profissionais com idade inferior a 30 anos. Tendo em vista que o erro amostral foi de 0,05, estimase com $95 \%$ de confiança que o número médio da idade dos profissionais envolvidos nas ocorrências éticas de enfermagem oscila de 35,63 a 38,09 anos.

Tabela 4 - Distribuição da freqüência das ocorrências, segundo a categoria dos profissionais de enfermagem envolvidos. São Paulo, 2005.

\begin{tabular}{lrr}
\hline Categoria & $\mathbf{N .}^{\mathbf{0}}$ & $\mathbf{0}$ \\
\hline Enfermeiro & 47 & 25,3 \\
Técnico de enfermagem & 45 & 24,2 \\
Auxiliar de enfermagem & 90 & 48,4 \\
Estagiário de enfermagem & 1 & 0,5 \\
Atendente de enfermagem & 3 & 1,6 \\
\hline Total & $\mathbf{1 8 6}$ & $\mathbf{1 0 0 , 0}$ \\
\hline
\end{tabular}

O exame dos dados contidos na Tabela 4 evidencia uma predominância da categoria auxiliar de enfermagem com $90(48,4 \%)$ das ocorrências éticas que foram enviadas à CEE, seguido da categoria enfermeiro com $47(25,3 \%)$ ocorrências e técnico de enfermagem com 45 (24,2\%) ocorrências.

Houve indicação de um caso envolvendo estagiário de enfermagem da graduação, o que representa $0,5 \%$ das ocorrências e três situações com atendentes de enfermagem, perfazendo 1,6\% do total de encaminhamentos à CEE.

Não é possível assegurar que os auxiliares de enfermagem são os profissionais mais propensos ao cometimento das ocorrências éticas, considerando que é preciso levar em consideração o fato dessa categoria estar composta de um contingente numérico maior, se comparados com outras categorias dentro da instituição estudada, conforme podemos constatar na tabela abaixo:

Tabela 5 - Distribuição do número médio de profissionais de enfermagem na instituição, no período de 1995 a 2004, segundo as categorias. São Paulo, 2005.

\begin{tabular}{lcc}
\hline Categoria & Média de $\mathbf{1 9 9 5 - 2 0 0 4}$ & $\mathbf{\%}$ \\
\hline Enfermeiro & 158 & 35,0 \\
Técnico de enfermagem & 99 & 22,0 \\
Auxiliar de enfermagem & 176 & 39,0 \\
Atendente de enfermagem & 18 & 4,0 \\
\hline Total & $\mathbf{4 5 1}$ & $\mathbf{1 0 0 , 0}$ \\
\hline
\end{tabular}

No período de 1995 a 2004, a média de profissionais de enfermagem foi de 451 profissionais/ano na instituição alvo do estudo, sendo que 35\% eram enfermeiros, $22 \%$ técnicos de enfermagem, $39 \%$ auxiliares de enfermagem e $4 \%$ atendentes de enfermagem.

Outros fatores podem estar imbricados com as ocorrências iatrogênicas no âmbito da saúde. Nesse sentido, a formação profissional das diversas categorias de enfermagem, o tempo de serviço na instituição, as 
experiências profissionais e as condições de trabalho são variáveis importantes em relação a tais ocorrências, seja em relação ao paciente, outros profissionais ou em relação à própria instituição de saúde ${ }^{(10)}$. Sendo assim, além de identificar o perfil dos profissionais envolvidos nas ocorrências éticas, é preciso, a nosso ver, conhecer o contexto de vida social e as condições de trabalho desses profissionais de enfermagem, a fim de compreender melhor os fatores que podem contribuir para as ocorrências éticas em enfermagem, possibilitando propostas de intervenção para minimizar ocorrências. Por outro lado, é compreensível que se espere uma atitude crítico-reflexiva maior por parte do enfermeiro, frente às ocorrências prejudiciais ao paciente/cliente, por ser o líder da equipe de enfermagem e coordenador de uma série de interações com outras categorias profissionais na área da saúde. Cabe-lhe, freqüentemente, a incumbência de avaliar, orientar, decidir e comunicar a ocorrência ética, envolvendo profissionais de enfermagem, para a Comissão de Ética ou para outras instâncias administrativas da instituição, ou mesmo externas à instituição, como é o caso dos encaminhamentos aos órgãos de fiscalização do exercício profissional, a fim de avaliar possível responsabilidade ética do profissional.

$\mathrm{Na}$ tabela seguinte, apontam-se os turnos e as freqüências das ocorrências éticas com os profissionais de enfermagem.

Tabela 6 - Distribuição dos profissionais de enfermagem envolvidos nas ocorrências éticas, segundo sua jornada de trabalho diária. São Paulo, 2005.

\begin{tabular}{lrr}
\hline Jornada de trabalho (dia) & N. $^{\mathbf{0}}$ & \multicolumn{1}{c}{$\mathbf{0}$} \\
\hline Seis horas & 107 & 57,5 \\
Oito horas & 2 & 1,1 \\
Noturno 12X36 h & 77 & 41,4 \\
\hline Total & $\mathbf{1 8 6}$ & $\mathbf{1 0 0 , 0}$ \\
\hline
\end{tabular}

O exame dos dados contidos na Tabela 6 mostra uma predominância de ocorrências com profissionais de enfermagem com jornada de trabalho, diária de seis horas, com 107 (57,5\%) dos casos levantados. Em seguida, vêm os profissionais com jornada de trabalho noturno de 12 por 36 horas, com $77(41,4 \%)$ e os com jornada diária de oito horas com 2 ocorrências (1,1\%). Na instituição, alvo do estudo, a jornada diária de 8 horas é mais freqüentemente assumida pelos enfermeiros que exercem cargos de chefia. Convém ressaltar, ainda, que de praxe são esses enfermeiros chefes que têm o poder decisório em relação ao encaminhamento das ocorrências nos setores em que são responsáveis, embora saibam que, do ponto de vista ético-legal, não haja essa exigência, ou seja, todo e qualquer profissional de enfermagem ou da saúde pode comunicar uma ocorrência ética à Comissão de Ética da respectiva categoria a que pertence o profissional envolvido.

O tempo de serviço dos profissionais que cometeram as ocorrências éticas é uma outra variável a ser ponderada na análise da tabela seguinte deste estudo.

Tabela 7 - Distribuição dos profissionais de enfermagem envolvidos nas ocorrências éticas, segundo o tempo de serviço. São Paulo, 2005.

\begin{tabular}{|c|c|c|}
\hline Tempo de serviço & N. ${ }^{o}$ & $\%$ \\
\hline Inferior a 3 meses & 72 & 38,7 \\
\hline 3 a 15 & 21 & 11,3 \\
\hline 16 a 36 & 30 & 16,1 \\
\hline 37 a 72 & 12 & 6,5 \\
\hline Acima de 72 & 49 & 26,3 \\
\hline Sem informação & 2 & 1,1 \\
\hline Total & 186 & 100,0 \\
\hline Média & \multicolumn{2}{|c|}{52,30} \\
\hline IC95\% & \multicolumn{2}{|c|}{10,97} \\
\hline Mediana & \multicolumn{2}{|c|}{14,00} \\
\hline Moda & \multicolumn{2}{|c|}{0} \\
\hline Desvio Padrão & \multicolumn{2}{|c|}{75,97} \\
\hline Mínimo & \multicolumn{2}{|c|}{0} \\
\hline Máximo & \multicolumn{2}{|c|}{336} \\
\hline Q1 & \multicolumn{2}{|c|}{0,00} \\
\hline Q2 & \multicolumn{2}{|c|}{14,00} \\
\hline Q3 & \multicolumn{2}{|c|}{84,00} \\
\hline
\end{tabular}

O exame dos dados contidos na Tabela 7 mostra uma predominância de profissionais de enfermagem com menos de três meses de serviço, com 72 (38,7\%) ocorrências; de três a 15 meses com 21 ocorrências $(11,3 \%)$, de 16 a 36 meses com 30 ocorrências (16,1\%); de 37 a 72 meses com 12 (6,5\%). Com mais de 72 meses de tempo de serviço na instituição com 49 ocorrências $(26,3 \%)$.

Quanto às medidas resumo, o valor médio do tempo de serviço foi de 52,3 meses ( $\mathrm{DP}=75,9$ ), com mediana de 14,0, moda de 0 e variação de 0 a 336 meses. Tendo em vista que o erro amostral foi de 0,05 estima-se com 95\% de confiança que o tempo de serviço médio dos profissionais de enfermagem envolvidos nas ocorrências éticas, no período estudado, oscila de 41,33 a 63,27 meses. Esse achado nos possibilita inferir que as ocorrências éticas com os profissionais nos primeiros meses, após a admissão na instituição, representam um percentual inferior ao esperado. Isso talvez se deva ao fato de que durante o período probatório o profissional esteja mais atento, sob supervisão constante e acompanhamento do enfermeiro da unidade. Mesmo porque, uma falha mais grave cometida pelo profissional recém admitido poderá interferir no momento da avaliação e efetivação, ou não, do candidato ao trabalho.

\section{CONCLUSÃO}

As ocorrências éticas podem ser consideradas causadoras de iatrogenias quando o agir do profissional 
se revelar displicente ou negligente em relação aos riscos correntes da assistência à clientela, tendo em vista que a previsibilidade dos riscos é uma variável importante para se aferir a responsabilidade profissional. Daí a necessidade de prevenção desses riscos. Ademais, faz-se mister enfatizar os aspectos positivos do cuidar seguro, ou seja, com isenção de riscos iatrogênicos ao cliente.

A maioria das ocorrências éticas envolveu profissionais de enfermagem do sexo feminino, sendo que a maioria dos casos foi comunicada à Comissão de Ética de Enfermagem da instituição pelos enfermeiros da instituição. Parte significativa dos envolvidos encontra-se na faixa etária de 30 a 39 anos (46,2\%), sendo que, aproximadamente, metade deles era pertencente à categoria de auxiliares de enfermagem. Cabe pontuar que essa categoria representou uma média de 39\% do contingente de enfermagem no período estudado. A jornada de trabalho de maior incidência das ocorrências é correspondente a seis horas diárias, envolvendo profissionais com mais de três meses de vínculo empregatício na instituição alvo do estudo.

Convém ressaltar que as ações gerenciais, em relação às ocorrências éticas, devem ser educativas e promovidas não só pela CEE, mas por todos os setores e gerências de enfermagem, com o compromisso institucional de apoiar a educação permanente dos profissionais de enfermagem. Com isso, o compromisso ético-político e a parceria dos profissionais no processo educativo podem resultar em uma assistência de enfermagem eficaz e segura ao cliente, com controle e prevenção de ocorrências éticas. Essa parceria requer também que haja investimento e capacitação dos profissionais, por parte da instituição de saúde, no sentido de prover adequação de recursos físicos, materiais e humanos ${ }^{(1)}$.

Um grande desafio que se lança à gerência de enfermagem é que ela seja tão imparcial que não se omita no encaminhamento de ocorrências éticas, mesmo que envolvam ações gerenciais.

\section{REFERÊNCIAS}

1. Brasil. Leis, Decretos, etc. Lei no 10.406 , de 10 de janeiro de 2002. São Paulo: Saraiva; 2002.

2. Freitas GF. Ocorrências éticas de enfermagem: uma abordagem compreensiva da ação social [tese]. São Paulo: Escola de Enfermagem da Universidade de São Paulo; 2005.

3. Zborowski IP, Melo MRAC. A Comissão de ética de enfermagem na visão do enfermeiro. Esc Anna Nery Rev Enferm. 2004; 8(2):224-34.

4. Código de Ética dos Profissionais de Enfermagem. In: Conselho Regional de Enfermagem de São Paulo. Documentos básicos de enfermagem: enfermeiros, técnicos, auxiliares. São Paulo: COREN-SP; 2001.

5. Oguisso T, Schmidt MJ. O exercício da enfermagem: uma abordagem ético-legal. São Paulo: Ltr; 1999.

6. Padilha KG. A prática de enfermagem em UTI e as ocorrências iatrogênicas: considerações sobre o contexto atual. Rev Paul Enferm. 2000; 19(3):49-56.

7. Padilha KG. Iatrogenias em unidade de terapia intensiva: uma abordagem teórica. Rev Paul Enferm. 1992; 11(2):6972.

8. Brasil. Leis, Decretos, etc. Lei n. 8.078, de 11 de setembro de 1990: dispõe sobre a proteção do consumidor e dá outras providências. Brasília: Imprensa Nacional; 1990. 12 p. (Suplemento ao n ${ }^{\circ} 176$ do Diário Oficial, de 12 de setembro de 1990).

9. Stevenson WJ. Estatística aplicada à administração. São Paulo: Harbra; 1997.

10. Siegel S. Estatística não-paramétrica para as ciências do comportamento. São Paulo: McGraw-Hill do Brasil; 1995. 